\title{
Expression profile of miRNA in NSCLC tissues in middle-altitude area
}

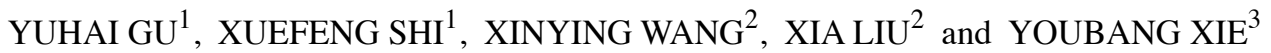 \\ ${ }^{1}$ Department of Respiratory Medicine, Qinghai Provincial People's Hospital, Xining, Qinghai 810007; \\ ${ }^{2}$ Graduate School of Qinghai University, Xining, Qinghai 810000; ${ }^{3}$ Department of Hematology, \\ Qinghai Provincial People's Hospital, Xining, Qinghai 810007, P.R. China
}

Received January 7, 2019; Accepted September 25, 2019

DOI: $10.3892 / 01.2019 .11176$

\begin{abstract}
Micro ribonucleic acid (miRNA) expression profile in non-small cell lung cancer (NSCLC) tissues in middle-altitude area was analyzed using the Affymetrix chip technique, to predict the target genes of abnormally-expressed miRNAs, and to analyze the target gene-related signaling pathways and cell biological functions regulated by them. The difference in miRNA expression profile in NSCLC tissues was analyzed using the Affymetrix chip technique. Reverse transcription-quantitative polymerase chain reaction (RT-qPCR) was performed for the verification of some differentially-expressed miRNAs. The genes predicted by at least 6 out of 12 commonly used prediction methods of miRNA target genes, based on miRWalk2.0, were considered as target genes. The functions of differentially-expressed miRNA target genes were analyzed via Gene Ontology (GO) enrichment analysis, and the main signaling pathways involving target genes were analyzed via Kyoto Encyclopedia of Genes and Genomes (KEGG) pathway enrichment analysis. There was abnormal expression of miRNAs in NSCLC tissues in the middle-altitude area. There were 140,405 target genes predicted for differentially-expressed miRNAs. The GO enrichment analysis of the functions of the target genes of differentially expressed miRNAs revealed that they mainly influence the binding process of intracellular components to protein, the positive regulation of biological process and the regulation of metabolic process. Moreover, these target genes were mainly enriched in the immunity, gene expression, metabolism and signal transduction, among which signal transduction was enriched with the most genes. The
\end{abstract}

Correspondence to: Dr Youbang Xie, Department of Hematology, Qinghai Provincial People's Hospital, 2 Gonghe Road, Xining, Qinghai 810007, P.R. China

E-mail: jieyoubang@163.com

Dr Xuefeng Shi, Department of Respiratory Medicine, Qinghai Provincial People's Hospital, 2 Gonghe Road, Xining, Qinghai 810007, P.R. China

E-mail: shu13654@126.com

Key words: middle-altitude, non-small cell lung cancer, cancer tissues, micro ribonucleic acid expression levels of miRNA-139-5p and miRNA-150-5p in lung cancer group were lower than those in the control group. The expression of miRNAs in NSCLC tissues in the middle-altitude area is abnormal, and most miRNAs are downregulated.

\section{Introduction}

There are numerous diagnostic methods for lung cancer, such as sputum pathology, tumor markers, imaging, CT scan, percutaneous lung puncture, and fiberoptic bronchoscopic and surgical tissue biopsy. Sputum cytologic culture is a traditional diagnostic method with high diagnostic specificity of $>98 \%$, but the sensitivity is only $66 \%$ (1). A trend toward lower sensitivity was noted for lesions that were $<2 \mathrm{~cm}$ in diameter. However, sensitivity is higher for central lesions than for peripheral lesions. Therefore, for lesions $<2 \mathrm{~cm}$ in diameter, CT is better than sputum cytology, especially in peripheral lung cancer. Although its diagnostic sensitivity is improved by cytologic smears, the arrangement mode of cancer cells is often changed during the smear process, harming the pathological diagnosis of lung cancer. There is a number of studies on the abnormal expression of micro ribonucleic acid (miRNA) in lung cancer tissues. However, the results are inconsistent or the biological functions remain unclear (1-3). The abnormal expression of miRNA is also related to environment and genetics, which also have prognostic risks (4). Whether the expression of miRNAs is inconsistent in lung cancer tissues and serum is unknown, and it has been reported that the miR-133 expression is increased in both lung cancer tissues and serum (5). According to the MeDIP-chip microarray analysis, there is methylation of miRNAs (miR-10b, miR-1179, miR-137, miR-572, miR-3150b and miR-129-2) in primary lung tumor, and miR-1179 mimics prevent cell growth through inhibiting the target gene CCNE1 (6).

miRNA is a kind of non-coding small-molecule RNA, which can target a variety of genes. miRNA is involved in regulating various biological processes, including the cell signal expression, proliferation, differentiation and apoptosis. Each miRNA can regulate hundreds of messenger RNAs (mRNAs) in a parallel and targeted manner, and any change in its expression level may produce significant influences on biological processes and lead to pathophysiological changes (7). Tumor cells are in a special hypoxic microenvironment, and hypoxia will occur once the tumor diameter becomes more than several 
hundred microns (8). The production of hypoxic environment and the activation of its major effector, hypoxia-inducible factor-1 (HIF-1), are common features of advanced cancer (9). Currently, there are few studies on whether the in vitro hypoxic state further aggravates the hypoxia in the microenvironment of lung cancer cells, and leads to abnormal expression of some miRNAs in lung cancer cells, and whether it is involved in the process of carcinogenesis, invasion and metastasis of lung cancer. A recent study found a significant correlation between Tibetan EGLN1/PHD2 haplotypes (D4E and C127S) and lung cancer, corresponding to a 2-fold increase of lung cancer risk in high altitude, and $\mathrm{a} \geq 2$-fold increased risk for rs117813469 and rs142764723 of the ten EPAS1/HIF-2 $\alpha$ variants (10), although the expression of miRNA is regulated by multiple factors. The tumor microenvironment, especially the effect of hypoxia on the biological characteristics of the tumor is clear. In the present study, lung cancer patients in middle-altitude area were enrolled to observe the effect of environmental hypoxia and tumor on the expression of miRNA. GeneChip scanning was performed on lung cancer tissues of 4 patients with non-small cell lung cancer (NSCLC) and 5 patients of the control group in the middle-altitude area. The differentially expressed miRNAs in cancer tissues were screened, the target genes of differentially expressed miRNAs were predicted, and the target gene-related signaling pathways and cell biological functions regulated by them were analyzed.

\section{Patients and methods}

Study subjects. A total of 30 patients admitted to the Respiratory and Critical Disease Department and Oncology Department of the Qinghai Provincial People's Hospital (Xining, China) from October 2016 to October 2017, who were definitely diagnosed with NSCLC via pathological biopsy of lung tissues (Fig. 1), were selected as the lung cancer group. There were 22 males and 8 females enrolled, with an average age of $64.58 \pm 12.56$ years and age range of 41-77 years. The cancer tissues of all lung cancer patients were obtained by surgical resection or percutaneous lung puncture, and were confirmed by immunohistochemistry. There were 17 cases of squamous cell carcinoma and 13 cases of adenocarcinoma, according to pathological classification. The clinical stage of the above NSCLC patients was $\mathrm{T}_{1-2} \mathrm{~N}_{0} \mathrm{M}_{0}$ for all the patients according to the WHO classification (11). The patients of the lung cancer group lived permanently in a middle-altitude area (altitude: 1,500-2,500 m), they were diagnosed initially with primary tumor and did not receive any treatment (chemoradiotherapy, molecular targeted therapy, or surgical resection), and had no malignant tumors in other organs. Further 34 non-tumor patients, admitted to the Qinghai Provincial People's Hospital during the same period and living permanently in a middle-altitude area, were selected as the control group, which included 24 males and 10 females with an average age of $59.36 \pm 14.08$ years and age range of 39-75 years. Samples were collected from marginal normal lung tissue obtained from non-tumor patients with pneumothorax by surgical resection. There were no significant differences in sex $\left(\chi^{2}=0.0594, \mathrm{P}=0.8074\right)$ and age $(\mathrm{t}=1.556, \mathrm{P}=0.1247)$ between the two groups $(\mathrm{P}>0.05)$, and thus, they were comparable. The patients of this study and/or their guardians were informed and signed an informed consent form. All study processes met the ethical requirements and were reviewed and approved by the Ethics Committee of the Qinghai Provincial People's Hospital (approval no. 2015-07).

RNA extraction, miRNA reverse transcription and miRNA polymerase chain reaction $(P C R)$. Total RNA was extracted from cells using the TRIzol reagent (Ambion; Thermo Fisher Scientific, Inc.). miRNA reverse transcription was performed using the TaqMan ${ }^{\circledR}$ MicroRNA Reverse Transcription kit (Applied Biosystems Life Technologies; Thermo Fisher Scientific, Inc.), and PCR primers corresponding to miRNAs were synthesized by Applied Biosystems (Thermo Fisher Scientific, Inc.). miRNA-16 was used as an internal reference. Sequences of miR-139-5p and miR-150-5p primers were: miRNA-139-5p forward, GTCGTATCCAGTGCAGGGTCC GAGGTATTCGCACTGGATACGACactgga and reverse, TCT ACAGTGCACGTGTCTCC; miRNA-150-5p forward, GTC GTATCCAGTGCAGGGTCCGAGGTATTCGCACTGGATA CGACcactgg and reverse, TCTCCCAACCCTTGTACC; miRNA-16 forward, GTCGTATCCAGTGCAGGGTCCGAG GTATTCGCACTGGATACGACcgccaa and reverse, GCTTGT AGCAGCACGTAAATATTG; miRNA-1 U6 forward, CTC GCTTCGGCAGCACA and reverse, AACGCTTCACGAATT TGCG. PCR was performed with QuantStudio ${ }^{\mathrm{TM}} 7$ Flex Real-Time PCR system (Thermo Fisher Scientific, Inc.) by using the $2^{-\Delta \Delta \mathrm{Cq}}$ method (12). Reaction system (15 $\left.\mu \mathrm{l}\right): 7 \mu \mathrm{l}$ Master Mix I $(0.15 \mu \mathrm{l}$ of $100 \mathrm{mM}$ dNTPs with dTTP, $1.00 \mu \mathrm{l}$ of $50 \mathrm{U} / \mu \mathrm{l}$ MultiScribe $^{\mathrm{TM}}$ Reverse Transcriptase, $1.5 \mu 1$ 10X Reverse Transcriptase Buffer, $0.19 \mu 1$ of $20 \mathrm{U} / \mu 1$ RNase Inhibitor, and $4.16 \mu \mathrm{l}$ nuclease-free water), $3 \mu \mathrm{l}$ 5X RT primer and $5 \mu \mathrm{l}$ RNA sample. Master Mix (MultiScribe ${ }^{\mathrm{TM}}$ Reverse Transcriptase, Reverse Transcriptase Buffer, RNase Inhibitor, nuclease-free water) was derived from TaqMan ${ }^{\circledR}$ MicroRNA Reverse Transcription kit. The reverse transcription conditions were: $16^{\circ} \mathrm{C}$ for $30 \mathrm{~min}, 42^{\circ} \mathrm{C}$ for $30 \mathrm{~min}$ and $85^{\circ} \mathrm{C}$ for $5 \mathrm{~min}$. RT-qPCR amplification system (20 $\mu 1): 1.00 \mu 1$ TaqMan Small Assay (20X; Applied Biosystems Life Technologies; Thermo Fisher Scientific, Inc.), $1.33 \mu \mathrm{l}$ product from RT reaction, $10 \mu \mathrm{l}$ TaqMan Universal PCR master mix II (2X; Applied Biosystems Life Technologies; Thermo Fisher Scientific, Inc.) and $7.67 \mu 1$ nuclease-free water. Amplification conditions were as follows: Option AmpErase UNG activity at $50^{\circ} \mathrm{C}$ for $2 \mathrm{~min}$, enzyme activation at $95^{\circ} \mathrm{C}$ for $10 \mathrm{~min}$, a total of 40 cycles, denaturation at $95^{\circ} \mathrm{C}$ for $15 \mathrm{sec}$, and annealing/extension at $60^{\circ} \mathrm{C}$ for $60 \mathrm{sec}$.

Immunohistochemistry. EnVision system (Dako; Agilent Technologies, Inc.) was used to detect the expression of TTF-1 (MAB-0599), NapsinA (MAB-0704), CK7 (MAB-0166), P40 (MAB-0666), CK5/6 (MAB-0276), and P63 (MAB-0365) proteins. All protein antibodies were purchased from Fuzhou Maixin Biotechnology Development Co., Ltd. Tissues were fixed in $4 \%$ neutral buffered formaldehyde for $24 \mathrm{~h}$ at room temperature. The experimental procedure was as follows: Paraffin-embedded tissues were cut into 3-4 $\mu \mathrm{m}$ and heated overnight at $65^{\circ} \mathrm{C}$. The tissue sections were deparaffinized and rehydrated. Inactivation of endogenous peroxidase $\left(3 \% \mathrm{H}_{2} \mathrm{O}_{2}\right.$, $10 \mathrm{~min}$ ) and washing with PBS for 3 times, every 2 min, were carried out. The antigen hot fix was EDTA, pH 9.0, $20 \mathrm{~min}$. The tissues were washed with PBS 3 times, every 2 min in distilled water prior to being blocked at room temperature 

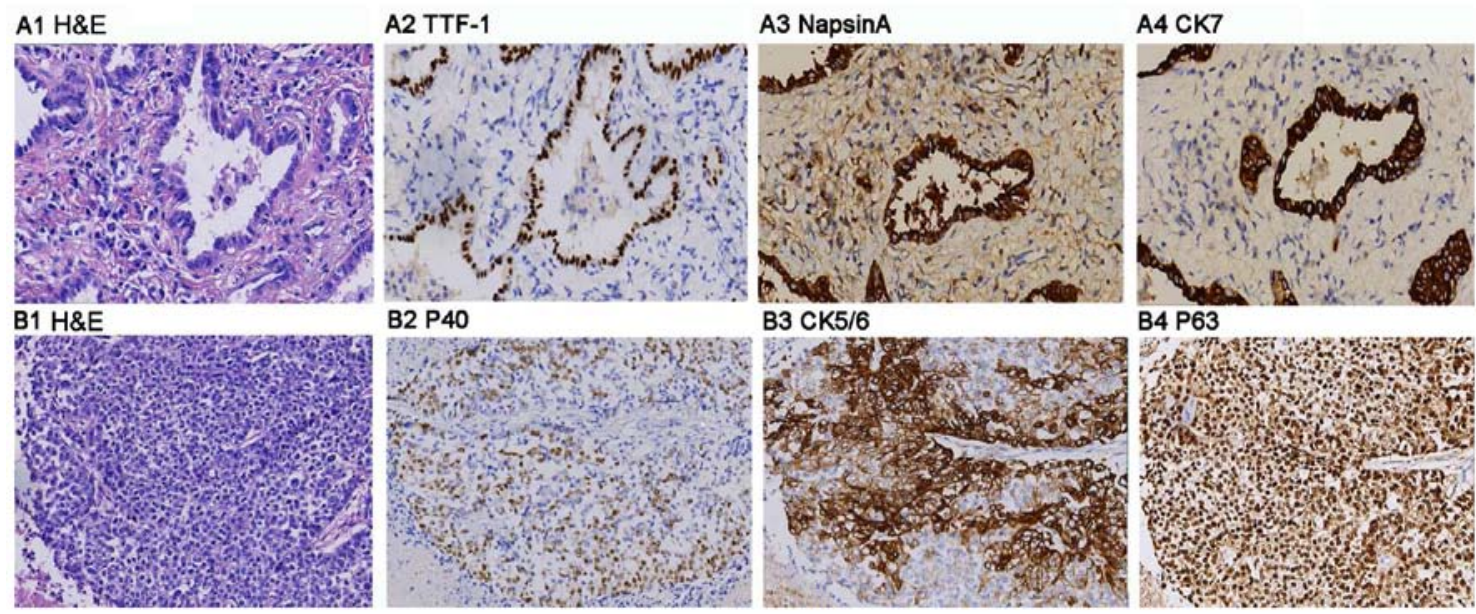

B4 P63

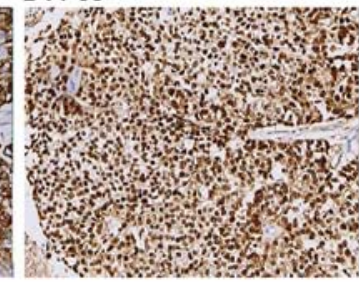

Figure 1. Immunohistochemistry of lung adenocarcinoma and lung squamous cell carcinoma tissues. (A-1) H\&E staining, (A-2) TTF-1 expression, (A-3) NapsinA expression, and (A-4) CK7 expression in lung adenocarcinoma tissues (x200). (B-1) H\&E staining, (B-2) P40 expression, (B-3) CK5/6 expression, and (B-4) P63 expression in lung squamous cell carcinoma tissues (x200).

for 10 min (goat serum working solution; Beijing Zhongshan Golden Bridge Biotechnology Co., Ltd.). Incubation with the primary antibody was carried out for $1 \mathrm{~h}$ at room temperature (with TTF-1 1:50, NapsinA 1:50, CK7 1:100, P40 1:50, CK5/6 1:100, P63 1:50) and then the tissues were washed with PBS 3 times, every $2 \mathrm{~min}$. Secondary antibody was added using MaxVision $^{\text {TM }}$ HRP-Polymer anti-Mouse/Rabbit IHC kit (cat no. 5010; Fuzhou Maixin Biotechnology Development Co., Ltd.) at room temperature for $25 \mathrm{~min}$. Washing with PBS for 3 times, every 2 min followed. DAB chromogenic reagent was used to detect the protein expression for 3-10 min (ready-to-use DAB color liquid, microscopic control). The slides were subsequently stained with hematoxylin and bluing was carried out. Sliced tissues were conducted with graded alcohol dehydration and xylene following the manufacturer's instructions. Leica DM2500 optical microscope (Leica Microsystems, Ltd.) was used for observation. H\&E staining in serial sections of each paraffin block specimens was performed for immunohistochemistry and expression analysis (Fig. 1).

GeneChip scanning of lung cancer tissues. Four patients diagnosed with NSCLC via pathological biopsy (E8, E2-t, E6-t and E9; Fig. 2A), and 5 non-tumor patients (C6, C8, C5, C1 and C3; Fig. 2A) were selected. The cancer and non-tumor tissues were collected and stored at $-80^{\circ} \mathrm{C}$ for Affymetrix GeneChip scanning (Affymetrix: Thermo Fisher Scientific, Inc.). Selection criteria for the lung cancer patients: i) Long-term residence in the middle-altitude area; ii) initial diagnosis of patients who did not receive any treatment (chemotherapy, molecular targeted therapy, or surgical resection); iii) patients with primary tumor; and iv) no other organ malignancy. Selection criteria for control patients: i) Patients with pneumothorax; and ii) no lung or other organ tumors. miRNAs were selected to expand the sample for verification, according to the following conditions: i) miRNAs consistently expressed according to the results of microarray and the published literature; ii) miRNAs with downregulated expression; and iii) miRNAs reported to be associated with lung cancer. miR-139-5p and miR-150-5p with obvious differential expression were verified by RT-qPCR with expanded sample size.

\section{Statistical analysis}

Chip difference analysis. The chip image information was converted into digital signal using the Affymetrix ${ }^{\circledR}$ GeneChip ${ }^{\circledR}$ Console ${ }^{\circledR}$ software (Affymetrix: Thermo Fisher Scientific, Inc.). The probe signal was integrated into the probeset signal, and the inter-sample variation caused by non-biological factors was removed via inter-chip normalization. The data were preprocessed using Range Migration Algorithm (RMA) (13). Differential genes were analyzed by Significance Analysis of Microarrays (SAM) R software package (https://www.rproject.org/), and the significant difference of chip data was analyzed. Differential genes were screened based on $\mathrm{P}<0.05$ and fold change $>2$ or $<0.5$.

Cluster analysis. Cluster analysis was performed for the differentially expressed miRNAs in the lung cancer and control groups using cluster software. Differentially expressed miRNAs were screened based on $\mathrm{P}<0.05$ and fold change $>2$ or $<0.5$.

Prediction and analysis of target genes of differentially expressed miRNAs. The genes predicted by at least 6 out of 12 commonly used prediction methods of miRNA target genes (miRWalk, DIANA-microTv4.0, miRanda-rel2010, mirBridge, miRDB4.0, miRmap, miRNAMap, PicTar2, PITA, RNA22v2, RNAhybrid2 and Targetscan6.2), based on miRWalk2.0 (14), were considered as target genes.

Functional enrichment analysis. Functional enrichment analysis was performed for the target genes of differentially expressed miRNAs using DAVID Bioinformatics Resources 6.7 (https://david.ncifcrf.gov/), including Gene Ontology (GO) enrichment analysis and pathway enrichment analysis (15). GO enrichment includes biological process, cell component and molecular function. The functional regulation image was plotted using the CytoScape software (https://cytoscape.org/) and Bingo plug-in, followed by input of the target genes. Pathway enrichment analysis mainly referred to Kyoto Encyclopedia of Genes and Genomes (KEGG) enrichment analysis (16).

Data analysis. Experimental measurement data were expressed as the mean \pm SD. SPSS 17.0 software (SPSS, Inc.) was used for statistical analysis. The log-rank P-values were obtained from a univariate Cox analysis, whereby miRNA expression was evaluated in response to patient survival time. Univariate Cox 


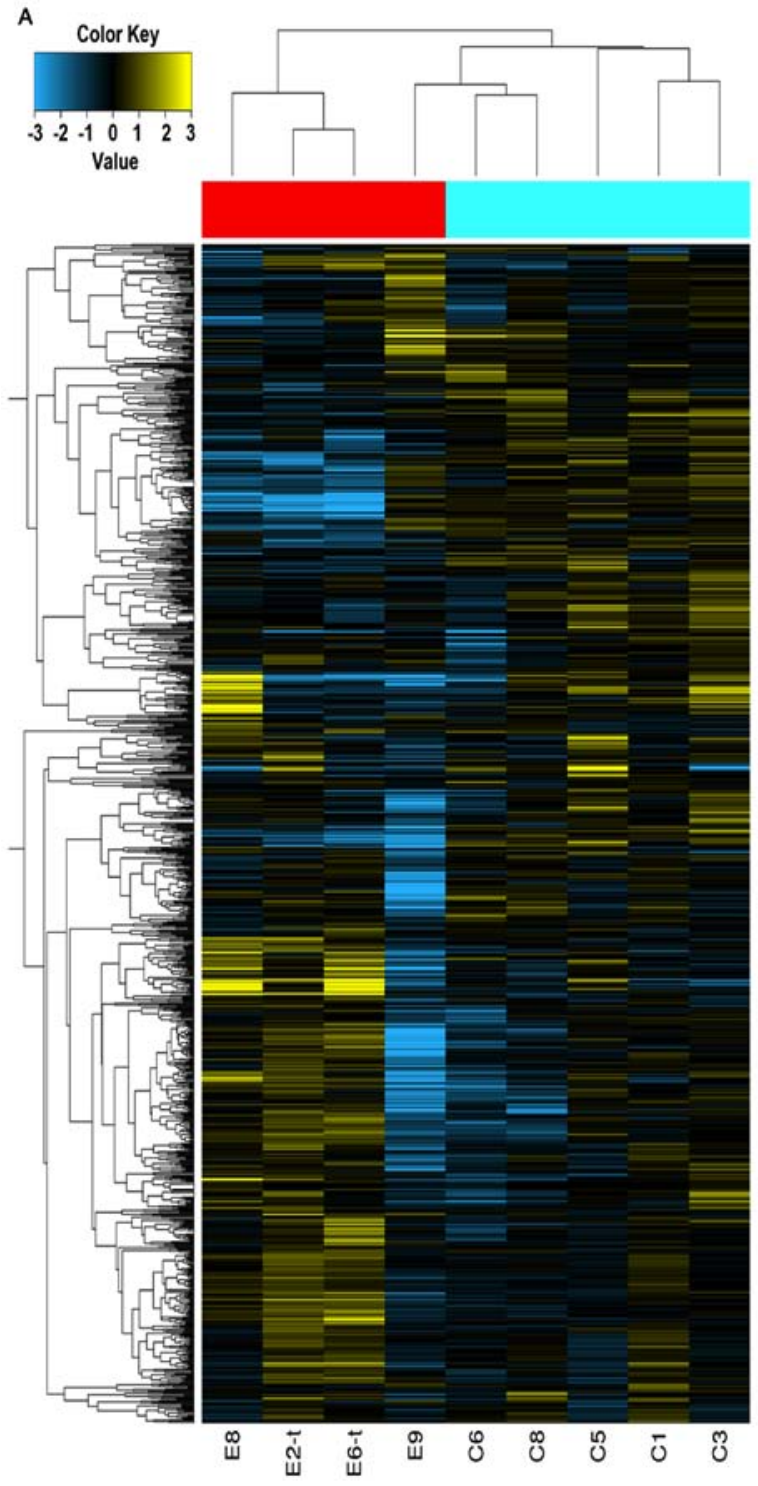

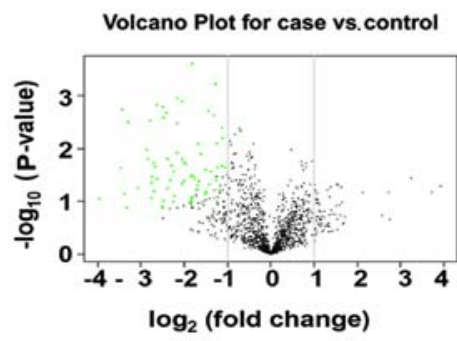

C

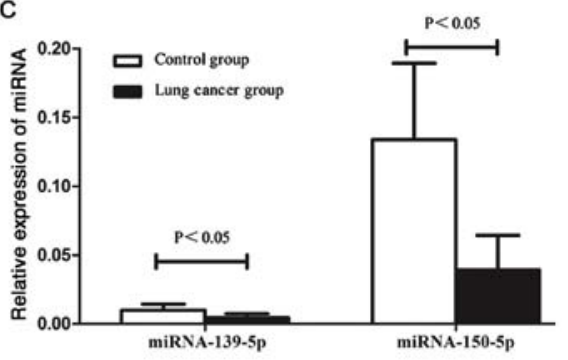

D
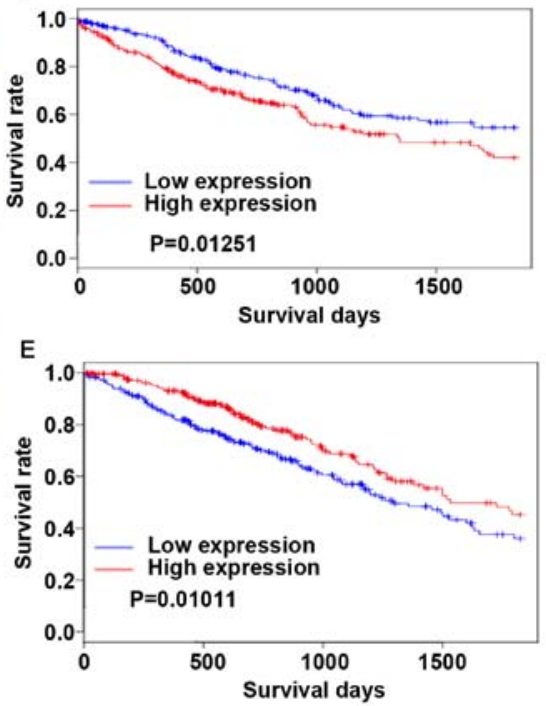

Figure 2. Global view of miRNA profile of NSCLC. miRNA expression profile of NSCLC was determined using Affymetrix oligoarrays. (A) Comparison of cluster data between NSCLC and non-tumor patients. (B) Volcano plot of differential miRNAs of NSCLC and non-tumor patients. The green dots on the left of the graph show the 76 downregulated miRNAs with fold change $<0.5$ in patients with NSCLC. (C) miRNA-139-5p and miRNA-150-5p in the lung cancer group (black column) were lower than those in the control group (white column), in accordance to the GeneChip results, displaying statistically significant differences $(\mathrm{P}<0.05)$. (D) Value of miR-139-5p low expression and miR-150-5p high expression for survival prognosis in lung squamous cell carcinoma. The low expression of miRNA-139-5p in lung squamous cell carcinoma shows good survival prognosis. (E) Value of miR-139-5p low expression and miR-150-5p high expression for survival prognosis in lung adenocarcinoma. The high expression of miRNA-150-5p in lung adenocarcinoma shows good survival prognosis. miRNA, micro ribonucleic acid; NSCLC, non-small cell lung cancer.

analysis also provided the Z-scores, which weighed the importance of the miRNA in response to these parameters. The t-test P-values were obtained from the Student's t-test, based on the patient vital status. $\log _{2}$ mean expression of the miRNA in the two survival cohorts was also obtained. The log-rank P-values were obtained from a univariate Cox analysis and survival characteristics of miRNA expression based on the Kaplan-Meier survival curves. The test level was set as $\alpha=0.05$. $\mathrm{P}<0.05$ was considered to indicate a statistically significant difference.

\section{Results}

Difference in miRNA expression profile of cancer tissues. The heatmap of gene expression in each group, obtained using the Cluster software, showed the difference in the expression of each gene in the different groups. Cluster analysis was performed for the miRNA expression in 4 cases in lung cancer group and 5 cases in normal group using the Cluster chip technique, and the differential genes were screened by the system according to the parameter setting and grouping, thus obtaining the distribution diagram (Fig. 2A) and list of differential genes. In the diagram with abscissa of $\log _{2}$ (fold change) and ordinate of $-\log _{10}$ (P-value), the data closer to the left and right bottom corresponded to the lower P-value, larger fold change and more significant difference (Fig. 2B). A total of 76 differentially expressed genes were screened, and no gene was upregulated (Table I).

Prediction results of target genes of differentially expressed miRNAs. There were 140,405 target genes predicted by at least 6 out of 12 commonly used prediction methods of miRNA target 
Table I. Differentially expressed miRNAs.

\begin{tabular}{|c|c|c|c|c|}
\hline Gene ID & Score $(d)$ & P-value (\%) & Fold change & Transcript ID (array design) \\
\hline 20503875 & -2.023293031 & 4.960182025 & 0.4813 & hsa-miR-500a-5p \\
\hline 20517816 & -2.640103593 & 2.254628193 & 0.4595 & hsa-miR-3609 \\
\hline 20506867 & -2.236471814 & 3.600132115 & 0.4578 & hsa-miR-1270 \\
\hline 20505746 & -2.693594792 & 2.254628193 & 0.4553 & hsa-miR-874-3p \\
\hline 20534325 & -2.080624824 & 4.650170648 & 0.4378 & HBII-85-2 \\
\hline 20534221 & -2.110884506 & 4.021769209 & 0.4247 & HBII-13 \\
\hline 20515540 & -2.093015723 & 4.021769209 & 0.4245 & hsa-miR-3136-5p \\
\hline 20500735 & -2.000720498 & 4.960182025 & 0.4214 & hsa-miR-130a-3p \\
\hline 20500713 & -2.539879295 & 2.254628193 & 0.4207 & hsa-let-7g-5p \\
\hline 20501201 & -2.201987788 & 3.600132115 & 0.4169 & hsa-miR-362-5p \\
\hline 20538284 & -3.541567197 & 0 & 0.4097 & mgU12-22-U4-8 \\
\hline 20538271 & -3.541567197 & 0 & 0.4097 & U91 \\
\hline 20500152 & -4.070180503 & 0 & 0.4022 & hsa-miR-26a-5p \\
\hline 20532691 & -2.339013412 & 2.861643476 & 0.3802 & ACA54 \\
\hline 20501280 & -2.324838379 & 2.861643476 & 0.3718 & hsa-miR-342-3p \\
\hline 20503908 & -3.378079284 & 0 & 0.3658 & hsa-miR-532-3p \\
\hline 20500490 & -2.234977738 & 3.600132115 & 0.354 & hsa-miR-224-3p \\
\hline 20500385 & -2.711696402 & 2.254628193 & 0.3511 & hsa-miR-192-5p \\
\hline 20534237 & -2.165774907 & 4.021769209 & 0.347 & HBII-289 \\
\hline 20500720 & -2.014983155 & 4.960182025 & 0.3424 & hsa-miR-23b-5p \\
\hline 20502122 & -3.132721492 & 0 & 0.3257 & hsa-miR-422a \\
\hline 20500400 & -2.507082441 & 2.254628193 & 0.3141 & hsa-miR-199a-3p \\
\hline 20500458 & -2.507082441 & 2.254628193 & 0.3141 & hsa-miR-199b-3p \\
\hline 20534233 & -3.222214722 & 0 & 0.311 & HBII-239 \\
\hline 20500444 & -2.425279357 & 2.861643476 & 0.3092 & hsa-miR-181a-5p \\
\hline 20500755 & -2.570514383 & 2.254628193 & 0.3083 & hsa-miR-145-5p \\
\hline 20500752 & -2.538495565 & 2.254628193 & 0.3037 & hsa-miR-143-3p \\
\hline 20501299 & -2.759869484 & 2.254628193 & 0.2934 & hsa-miR-339-3p \\
\hline 20511549 & -2.513431114 & 2.254628193 & 0.2843 & hsa-miR-2110 \\
\hline 20504584 & -2.06130082 & 4.650170648 & 0.2833 & hsa-miR-378d \\
\hline 20534249 & -4.614743071 & 0 & 0.2831 & HBII-436 \\
\hline 20500149 & -2.092452784 & 4.021769209 & 0.2805 & hsa-miR-24-2-5p \\
\hline 20500746 & -2.266082512 & 3.600132115 & 0.2794 & hsa-miR-140-3p \\
\hline 20500179 & -2.385781433 & 2.861643476 & 0.2772 & hsa-miR-98-5p \\
\hline 20500399 & -2.157881528 & 4.021769209 & 0.2706 & hsa-miR-199a-5p \\
\hline 20500796 & -2.646379389 & 2.254628193 & 0.256 & hsa-miR-193a-3p \\
\hline 20500786 & -2.165642544 & 4.021769209 & 0.2491 & hsa-miR-184 \\
\hline 20501183 & -2.681288323 & 2.254628193 & 0.2485 & hsa-miR-30e-3p \\
\hline 20532631 & -2.389108936 & 2.861643476 & 0.2431 & ACA20 \\
\hline 20534505 & -3.419080689 & 0 & 0.2411 & hsa-mir-139 \\
\hline 20500724 & -4.572998345 & 0 & 0.2405 & hsa-miR-30b-5p \\
\hline 20500470 & -1.995623568 & 4.960182025 & 0.2404 & hsa-miR-181a-3p \\
\hline 20501242 & -4.40904384 & 0 & 0.223 & hsa-miR-378a-5p \\
\hline 20500777 & -3.304790153 & 0 & 0.222 & hsa-miR-138-1-3p \\
\hline 20500457 & -2.798683433 & 0 & 0.2213 & hsa-miR-199b-5p \\
\hline 20500472 & -2.479406791 & 2.254628193 & 0.2133 & hsa-miR-214-3p \\
\hline 20500725 & -3.281305219 & 0 & 0.2105 & hsa-miR-30b-3p \\
\hline 20500798 & -2.266005058 & 3.600132115 & 0.2084 & hsa-miR-195-5p \\
\hline 20500455 & -2.443075633 & 2.861643476 & 0.2025 & hsa-miR-187-3p \\
\hline 20504378 & -2.961664196 & 0 & 0.1999 & hsa-miR-628-3p \\
\hline 20500769 & -2.748124213 & 2.254628193 & 0.1907 & hsa-miR-126-3p \\
\hline 20500421 & -3.140677949 & 0 & 0.1907 & hsa-miR-148a-3p \\
\hline
\end{tabular}


Table I. Continued.

\begin{tabular}{|c|c|c|c|c|}
\hline Gene ID & Score $(d)$ & P-value (\%) & Fold change & Transcript ID (array design) \\
\hline 20500751 & -3.615143592 & 0 & 0.1878 & hsa-miR-143-5p \\
\hline 20500181 & -2.252023278 & 3.600132115 & 0.1792 & hsa-miR-99a-5p \\
\hline 20501159 & -3.522911239 & 0 & 0.1785 & hsa-miR-29c-5p \\
\hline 20501160 & -2.004342033 & 4.960182025 & 0.1766 & hsa-miR-29c-3p \\
\hline 20500433 & -4.0848626 & 0 & 0.1765 & hsa-miR-139-3p \\
\hline 20503809 & -2.106652473 & 4.021769209 & 0.1749 & hsa-miR-497-5p \\
\hline 20503793 & -2.877805839 & 0 & 0.1612 & hsa-miR-146b-5p \\
\hline 20500745 & -4.285173248 & 0 & 0.1605 & hsa-miR-140-5p \\
\hline 20500448 & -3.262063359 & 0 & 0.1563 & hsa-miR-181c-5p \\
\hline 20501278 & -2.530236435 & 2.254628193 & 0.153 & hsa-miR-328-3p \\
\hline 20532991 & -2.436811645 & 2.861643476 & 0.1529 & ENSG00000207118 \\
\hline 20518919 & -2.947617982 & 0 & 0.1481 & hsa-miR-4521 \\
\hline 20500189 & -2.469462691 & 2.254628193 & 0.1474 & hsa-miR-29b-2-5p \\
\hline 20500767 & -3.049601189 & 0 & 0.147 & hsa-miR-125b-2-3p \\
\hline 20500471 & -4.243698759 & 0 & 0.1436 & hsa-miR-214-5p \\
\hline 20501279 & -4.160054969 & 0 & 0.139 & hsa-miR-342-5p \\
\hline 20503786 & -3.059282787 & 0 & 0.137 & hsa-miR-489-3p \\
\hline 20500163 & -2.907652913 & 0 & 0.1189 & hsa-miR-30a-3p \\
\hline 20500154 & -4.609102845 & 0 & 0.1011 & hsa-miR-26b-5p \\
\hline 20501237 & -2.009850173 & 4.960182025 & 0.0991 & hsa-miR-375 \\
\hline 20500743 & -2.406363169 & 2.861643476 & 0.096 & hsa-miR-138-5p \\
\hline 20500423 & -6.212996193 & 0 & 0.0923 & hsa-miR-30c-2-3p \\
\hline 20500782 & -3.711337554 & 0 & 0.0907 & hsa-miR-150-5p \\
\hline 20500432 & -2.542450843 & 2.254628193 & 0.0639 & hsa-miR-139-5p \\
\hline
\end{tabular}

miRNA, micro ribonucleic acid.

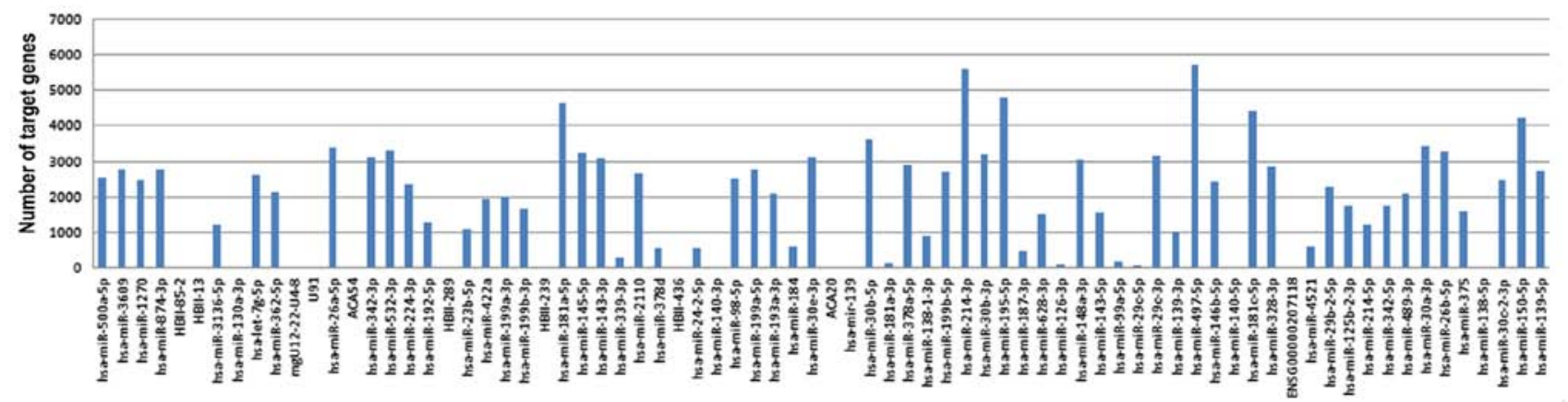

Figure 3. Number of target genes of differentially expressed miRNAs. Target genes were predicted by at least 6 out of 12 commonly used prediction methods of miRNA target genes. The maximum number of target genes predicted was 5,715 for miRNA-497-5p. The second highest number of target genes was 5,588 for miRNA-214-3p, and the third highest was 4,796 for miRNA-195-5p. miRNA, micro ribonucleic acid.

genes (miRWalk, DIANA-microTv4.0, miRanda-rel2010, mirBridge, miRDB4.0, miRmap, miRNAMap, PicTar2, PITA, RNA22v2, RNAhybrid2 and Targetscan6.2) based on miRWalk2.0 (Fig. 3).

Enrichment analysis of predicted target genes of differentially expressed miRNAs. GO enrichment analysis and KEGG pathway enrichment analysis were performed for the target genes obtained.
GO enrichment analysis. The analysis of the functions of target genes of differentially expressed miRNAs via GO enrichment revealed that they mainly influenced the binding process of intracellular components to protein, the positive regulation of biological process and the regulation of metabolic process (Table II and Fig. 4).

KEGG enrichment analysis. KEGG pathway enrichment analysis showed that these target genes were mainly enriched in the immunity, gene expression, metabolism and signal 
Table II. Top 30 functions of target genes predicted by Gene Ontology enrichment analysis.

\begin{tabular}{|c|c|c|c|}
\hline Term & ID & Input no. & P-value \\
\hline Intracellular part & GO:0044424 & 10,337 & 4.88E-86 \\
\hline Intracellular & GO:0005622 & 10,575 & $8.05 \mathrm{E}-85$ \\
\hline Binding & GO:0005488 & 10,658 & $5.45 \mathrm{E}-82$ \\
\hline Protein binding & GO:0005515 & 8,315 & $7.84 \mathrm{E}-77$ \\
\hline Organelle & GO:0043226 & 9,722 & $3.48 \mathrm{E}-61$ \\
\hline Membrane-bounded organelle & GO:0043227 & 9,087 & $4.35 \mathrm{E}-60$ \\
\hline Intracellular organelle & GO:0043229 & 9,017 & $1.16 \mathrm{E}-59$ \\
\hline Cytoplasm & GO:0005737 & 8,121 & $1.14 \mathrm{E}-57$ \\
\hline Positive regulation of biological process & GO:0048518 & 4,488 & $1.7 \mathrm{E}-57$ \\
\hline Regulation of metabolic process & GO:0019222 & 5,396 & $2.95 \mathrm{E}-56$ \\
\hline Intracellular membrane-bounded organelle & GO:0043231 & 8,249 & $2.35 \mathrm{E}-55$ \\
\hline Positive regulation of cellular process & GO:0048522 & 3,863 & $6.5 \mathrm{E}-55$ \\
\hline System development & GO:0048731 & 3,452 & $9.28 \mathrm{E}-54$ \\
\hline Anatomical structure development & GO:0048856 & 4,310 & $1.25 \mathrm{E}-50$ \\
\hline Regulation of cell communication & GO:0010646 & 2,730 & $3.08 \mathrm{E}-50$ \\
\hline Multicellular organismal development & GO:0007275 & 3,869 & 5.33E-50 \\
\hline Developmental process & GO:0032502 & 4,556 & $2.3 \mathrm{E}-48$ \\
\hline Regulation of signaling & GO:0023051 & 2,705 & $8.05 \mathrm{E}-48$ \\
\hline Single-organism developmental process & GO:0044767 & 4,484 & $7.71 \mathrm{E}-47$ \\
\hline Metabolic process & GO:0008152 & 8,668 & $1.17 \mathrm{E}-46$ \\
\hline Ion binding & GO:0043167 & 4,768 & $3.55 \mathrm{E}-45$ \\
\hline Regulation of cellular metabolic process & GO:0031323 & 4,694 & $2.12 \mathrm{E}-43$ \\
\hline Nervous system development & GO:0007399 & 1,794 & $3.64 \mathrm{E}-43$ \\
\hline Intracellular signal transduction & GO:0035556 & 2,336 & $9.01 \mathrm{E}-43$ \\
\hline Cellular metabolic process & GO:0044237 & 7,818 & $1.84 \mathrm{E}-42$ \\
\hline Positive regulation of metabolic process & GO:0009893 & 3,020 & $2.44 \mathrm{E}-42$ \\
\hline Anatomical structure morphogenesis & GO:0009653 & 2,103 & $1.42 \mathrm{E}-40$ \\
\hline Regulation of macromolecule metabolic process & GO:0060255 & 4,502 & $2.42 \mathrm{E}-40$ \\
\hline Cytoplasmic part & GO:0044444 & 6,197 & $3.54 \mathrm{E}-40$ \\
\hline Cellular macromolecule metabolic process & GO:0044260 & 6,384 & 9.37E-40 \\
\hline
\end{tabular}

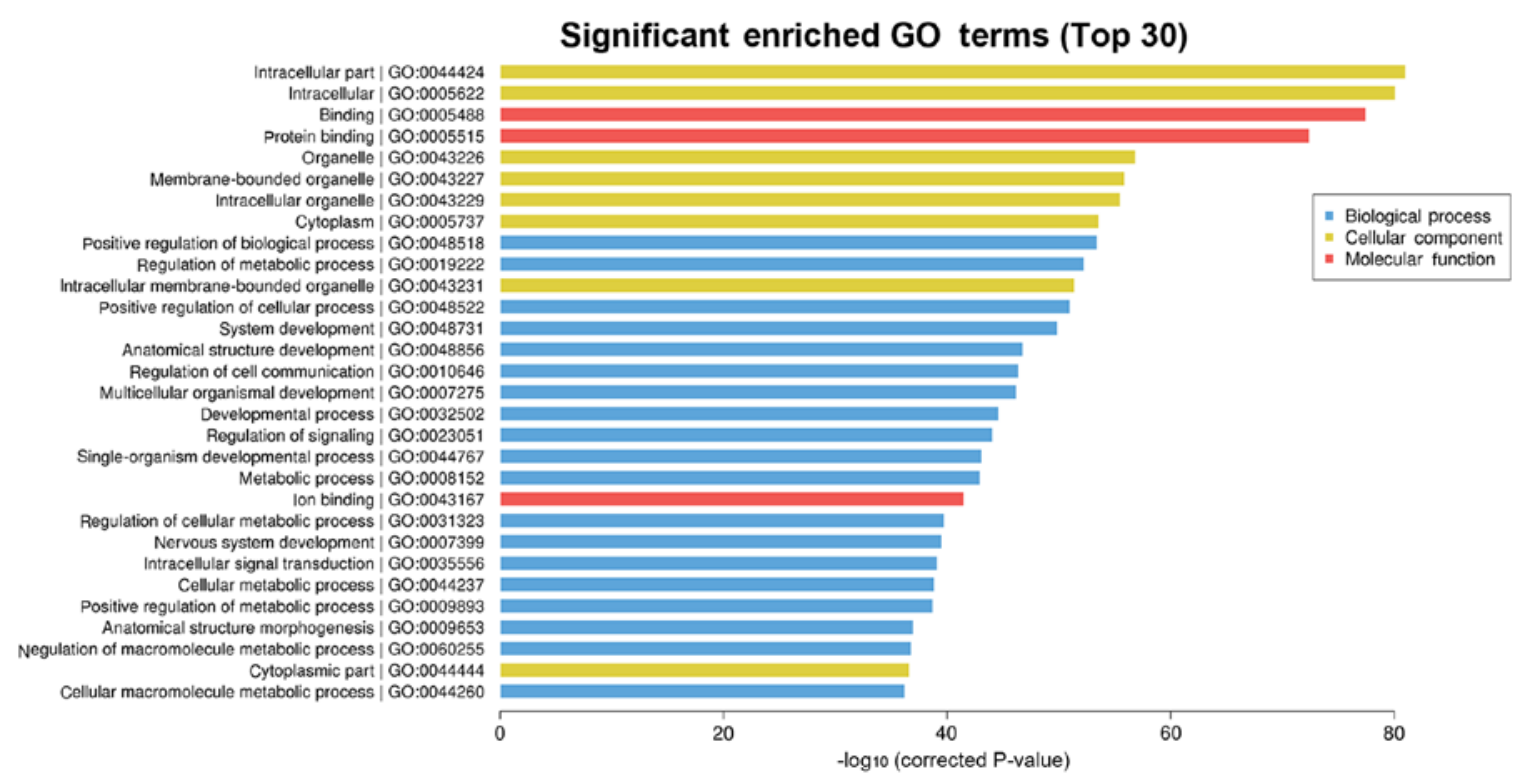

Figure 4. Top 30 functions of target genes predicted by GO enrichment analysis. The top 30 functions are classified into three categories, i.e., biological processes, cellular components and molecular functions. Among them, 19 functions are related to biological processes which mainly influence the positive regulation of biological processes, metabolic processes and cellular processes. Eight functions are related to cellular components which mainly influence intracellular components, and 3 functions are related to molecular functions which mainly influence protein binding and ion binding. GO, Gene Ontology. 
Table III. Top 30 signaling pathways by Kyoto Encyclopedia of Genes and Genomes pathway enrichment analysis.

\begin{tabular}{llrr}
\hline Term & \multicolumn{1}{c}{ ID } & Input no. & P-value \\
\hline Immune system & R-HSA-168256 & 1,223 & $1.86 \mathrm{E}-14$ \\
Developmental biology & R-HSA-1266738 & 687 & $3.37 \mathrm{E}-11$ \\
Gene expression & R-HSA-74160 & 1,266 & $5.31 \mathrm{E}-11$ \\
Generic transcription pathway & R-HSA-212436 & 668 & $5.66 \mathrm{E}-11$ \\
Axon guidance & R-HSA-422475 & 475 & $2.44 \mathrm{E}-10$ \\
Membrane trafficking & R-HSA-199991 & 459 & $1.69 \mathrm{E}-09$ \\
Vesicle-mediated transport & R-HSA-5653656 & 481 & $3.53 \mathrm{E}-09$ \\
Adaptive immune system & R-HSA-1280218 & 623 & $4.57 \mathrm{E}-09$ \\
Metabolism & R-HSA-1430728 & 1,388 & $1.7 \mathrm{E}-08$ \\
Transmembrane transport of small molecules & R-HSA-382551 & 530 & $2.38 \mathrm{E}-08$ \\
Pathways in cancer & hsa05200 & 345 & $5.64 \mathrm{E}-08$ \\
Signaling by NGF & R-HSA-166520 & 374 & $9.21 \mathrm{E}-08$ \\
Hemostasis & R-HSA-109582 & 486 & $1.11 \mathrm{E}-07$ \\
Metabolic pathways & hsa01100 & 896 & $2.36 \mathrm{E}-07$ \\
Disease & R-HSA-1643685 & 676 & $5.16 \mathrm{E}-07$ \\
Innate immune system & R-HSA-168249 & 582 & $9.72 \mathrm{E}-07$ \\
Cytokine signaling in immune system & R-HSA-1280215 & 486 & $1.14 \mathrm{E}-06$ \\
Metabolism of lipids and lipoproteins & R-HSA-556833 & 541 & $1.62 \mathrm{E}-06$ \\
PI3K-Akt signaling pathway & hsa04151 & 289 & $2.22 \mathrm{E}-06$ \\
Endocytosis & hsa04144 & 232 & $2.25 \mathrm{E}-06$ \\
Neuronal system & R-HSA-112316 & 288 & $2.38 \mathrm{E}-06$ \\
NGF signaling via TRKA from the plasma membrane & R-HSA-187037 & 304 & $2.86 \mathrm{E}-06$ \\
Signaling by PDGF & R-HSA-186797 & 299 & $2.93 \mathrm{E}-06$ \\
Post-translational protein modification & R-HSA-597592 & 625 & $3.14 \mathrm{E}-06$ \\
Wnt signaling pathway & P00057 & $3.36 \mathrm{E}-06$ \\
Fc epsilon receptor signaling & R-HSA-2454202 & 254 & $4.37 \mathrm{E}-06$ \\
Extracellular matrix organization & R-HSA-1474244 & 293 & $5.24 \mathrm{E}-06$ \\
Proteoglycans in cancer & hsa05205 & 250 & $6.53 \mathrm{E}-06$ \\
Signal transduction & R-HSA-162582 & 188 & $6.87 \mathrm{E}-06$ \\
Metabolism of proteins & R-HSA-392499 & 1,634 & 965 \\
\end{tabular}

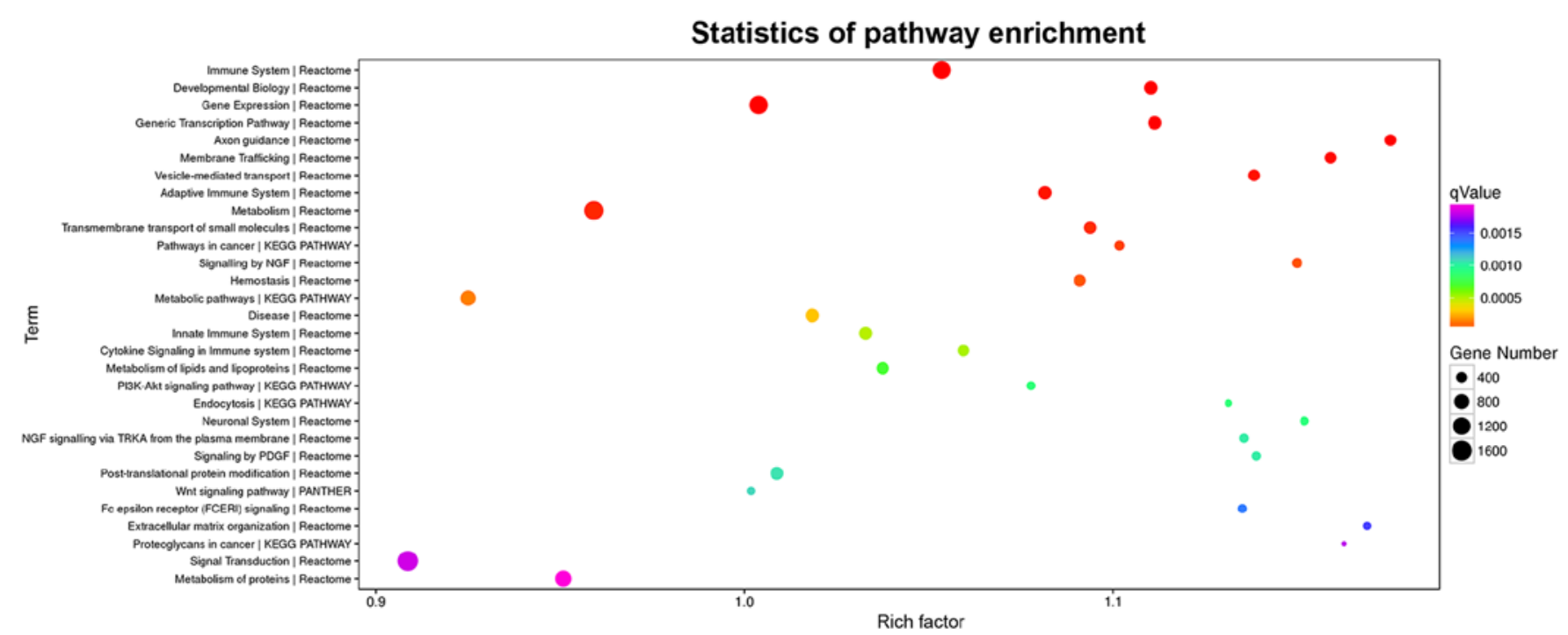

Figure 5. Top 30 signaling pathways by KEGG pathway enrichment analysis. The top 30 signaling pathways of the differentially expressed miRNAs were obtained by KEGG enrichment analysis. The size of each dot represents the amount of gene enrichment. The larger the dot, the more genes are enriched. The smaller the dot, the smaller the number of the genes enriched. The color of each dot represents the P-value. The more red the dot, the smaller the P-value. KEGG pathway enrichment analysis showed that these target genes are mainly enriched in the immunity, gene expression, metabolism and signal transduction, among which signal transduction was enriched with the most genes. KEGG, Kyoto Encyclopedia of Genes and Genomes; miRNA, micro ribonucleic acid. 
Table IV. Top 30 related diseases by disease enrichment analysis.

\begin{tabular}{|c|c|c|c|}
\hline Term & Database ID & Input no. & P-value \\
\hline Obesity-related traits & NHGRI GWAS Catalog & 553 & $9.65 \mathrm{E}-09$ \\
\hline Nervous system diseases & KEGG DISEASE & 469 & 4.65E-08 \\
\hline Other nervous and sensory system diseases & KEGG DISEASE & 364 & $1.11 \mathrm{E}-06$ \\
\hline Other congenital disorders & KEGG DISEASE & 370 & 4.66E-06 \\
\hline Congenital disorders of metabolism & KEGG DISEASE & 442 & $6.5 \mathrm{E}-06$ \\
\hline Height & NHGRI GWAS Catalog & 381 & 7.71E-06 \\
\hline Schizophrenia & NHGRI GWAS Catalog & 341 & $2.43 \mathrm{E}-05$ \\
\hline Musculoskeletal diseases & KEGG DISEASE & 226 & $3.18 \mathrm{E}-05$ \\
\hline Body mass index & NHGRI GWAS Catalog & 266 & 8.04E-05 \\
\hline Cancers & KEGG DISEASE & 182 & $9.03 \mathrm{E}-05$ \\
\hline Congenital disorders of development & KEGG DISEASE & 250 & 0.000146 \\
\hline Inflammatory bowel disease & NHGRI GWAS Catalog & 221 & 0.00015 \\
\hline Skeletal diseases & KEGG DISEASE & 169 & 0.000159 \\
\hline Others & KEGG DISEASE & 128 & 0.000344 \\
\hline Skin diseases & KEGG DISEASE & 155 & 0.000494 \\
\hline Skin and soft tissue diseases & KEGG DISEASE & 155 & 0.000494 \\
\hline Amyotrophic lateral sclerosis (sporadic) & NHGRI GWAS Catalog & 137 & 0.000534 \\
\hline Cardiovascular diseases & KEGG DISEASE129 & 223 & 0.000678 \\
\hline Menarche (age at onset) & NHGRI GWAS Catalog & 145 & 0.000978 \\
\hline Crohn's disease & NHGRI GWAS Catalog & 200 & 0.00128 \\
\hline Type 2 diabetes & NHGRI GWAS Catalog & 150 & 0.001504 \\
\hline Neurodegenerative diseases & KEGG DISEASE & 132 & 0.002359 \\
\hline Immune system diseases & KEGG DISEASE & 186 & 0.003778 \\
\hline Diisocyanate-induced asthma & NHGRI GWAS Catalog & 135 & 0.004021 \\
\hline Congenital disorders of amino acid metabolism & KEGG DISEASE & 102 & 0.004472 \\
\hline Kidney diseases & KEGG DISEASE & 72 & 0.004562 \\
\hline Urinary system diseases & KEGG DISEASE & 72 & 0.004562 \\
\hline HDL cholesterol & NHGRI GWAS Catalog & 112 & 0.004949 \\
\hline Rheumatoid arthritis & NHGRI GWAS Catalog & 114 & 0.005032 \\
\hline Breast cancer & NHGRI GWAS Catalog & 100 & 0.005145 \\
\hline
\end{tabular}

transduction, among which signal transduction was enriched with the most genes (Table III and Fig. 5).

Disease enrichment analysis. The tenth disease enriched was cancer (Table IV and Fig. 6).

Comparison of miRNA-139-5p and miRNA-150-5p relative expression levels between the lung cancer and control group and its influence on prognosis. According to RT-qPCR verification with an expanded sample size, the expression levels of miRNA-139-5p and miRNA-150-5p in lung cancer group were lower than those in control group, in accordance to the GeneChip results, displaying statistically significant differences $(\mathrm{P}<0.05)$ (Fig. 2C). The use of online resources (http://www. oncomir.org/) predicted that low-expression miRNA-139-5p in lung squamous cell carcinoma and high-expression miRNA-150-5p in lung adenocarcinoma have a good prognosis (Tables V and VI, Fig. 2D and E).

\section{Discussion}

NSCLC is a kind of solid tumor that is often diagnosed in the late stage, due to the lack of specific early symptoms, resulting in fewer opportunities for operation. Moreover, most of the samples in clinical survey are obtained via bronchoscopic small biopsy or cytology, so the number of tumor cells available is small with poor quality. miRNAs, as a kind of biomarkers, have expression dysregulation in the resected primary NSCLC tissues (17), which plays important roles in the classification of lung cancer subtypes, prognosis of patient, and sensitivity to chemotherapy $(18,19)$. In the present study, a comprehensive miRNA expression profile was identified, and abnormally expressed miRNAs in tumor tissues were confirmed, providing references for the in-depth research on the role of miRNAs in occurrence and development of tumors.

According to the systematic analysis of miRNA in various human cancers and 217 types of mammals, the miRNA profile has a surprising amount of information, reflecting the developmental lineage and differentiation status of tumors. miRNAs in tumors are generally downregulated, compared with those in normal tissues, and the miRNA expression profile is valuable for the classification of poorly differentiated tumors (20). The results of this study are consistent with those in the above studies: All of the 76 differentially expressed miRNAs screened were downregulated, and no differentially expressed miRNAs were upregulated. miRNAs are a kind of non-coding regulatory RNAs involved in the occurrence of 


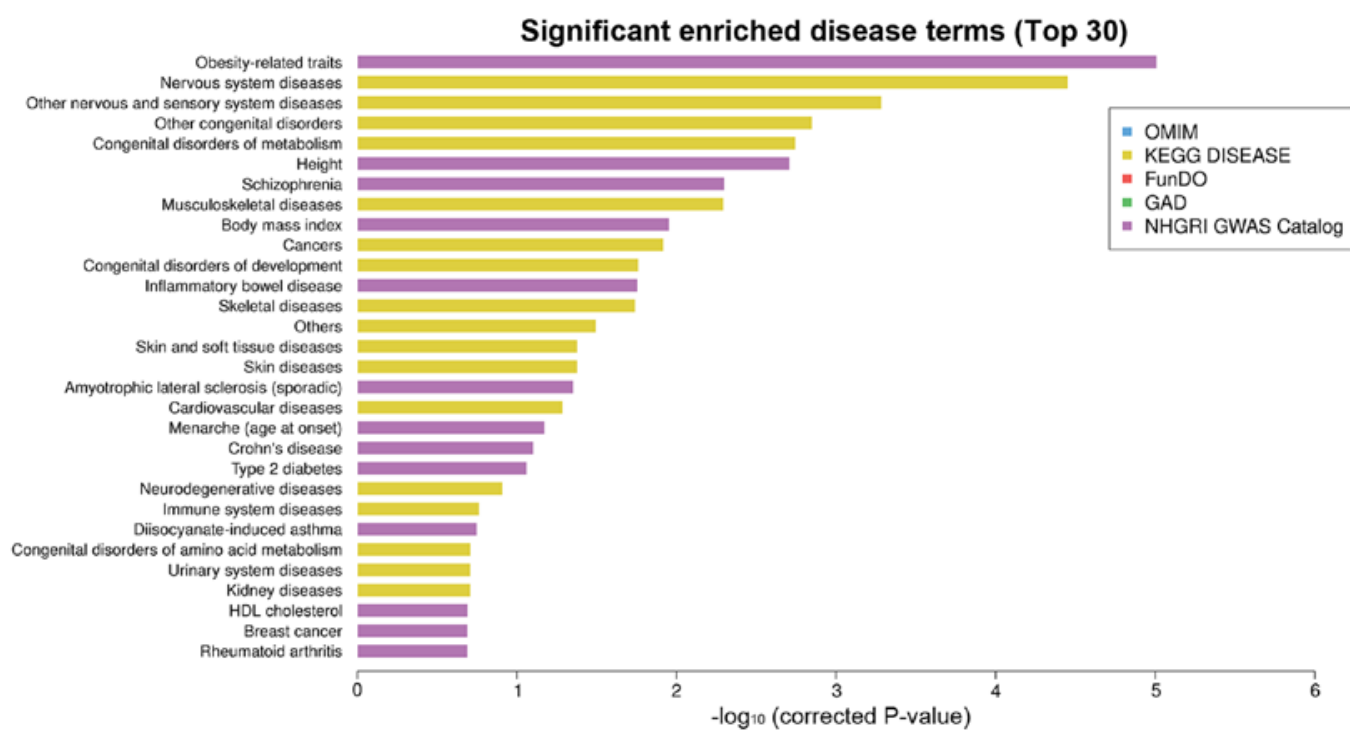

Figure 6. Top 30 related diseases by disease enrichment analysis. The top 30 related diseases of the differentially expressed miRNAs obtained by OMIM, KEGG, FunDO, GAD and NHGRI GWAS Catalog enrichment analyses. The length of each bar represents the P-value. The longer the bar, the smaller the P-value. Among the top 30 related diseases mainly enriched by KEGG and NHGRI GWAS, the 10th disease enriched was cancer. miRNA, micro ribonucleic acid; OMIM, Online Mendelian Inheritance in Man; KEGG, Kyoto Encyclopedia of Genes and Genomes; FunDO, Functional Disease Ontology; GAD, Genetic Association Database; NHGRI, National Human Genome Research Institute; GWAS, genome-wide association study.

Table V. Cancer types where survival is significantly associated with miR-139-5p and miR-150-5p.

\begin{tabular}{|c|c|c|c|c|c|c|c|c|c|}
\hline \multirow[b]{2}{*}{ miRNA } & \multirow[b]{2}{*}{ Cancer } & \multicolumn{2}{|c|}{ Log-rank } & \multirow[b]{2}{*}{ Z-score } & \multirow[b]{2}{*}{ Upregulated in } & \multirow{2}{*}{$\begin{array}{c}\text { Deceased } \\
\log _{2} \text { mean } \\
\text { expression }\end{array}$} & \multirow{2}{*}{$\begin{array}{c}\text { Living } \\
\log _{2} \text { mean } \\
\text { expression }\end{array}$} & \multicolumn{2}{|c|}{ t-test } \\
\hline & & P-value & FDR & & & & & P-value & FDR \\
\hline miR-139-5p & LUSC & $1.55 \mathrm{e}-02$ & $9.92 \mathrm{e}-01$ & 2.452 & Deceased & 5.00 & 4.82 & $2.16 \mathrm{e}-01$ & $7.43 \mathrm{e}-01$ \\
\hline $\operatorname{miR}-150-5 p$ & LUAD & $7.52 \mathrm{e}-03$ & $9.56 \mathrm{e}-02$ & 2.693 & Living & 9.94 & 10.18 & $4.22 \mathrm{e}-02$ & $4.85 \mathrm{e}-01$ \\
\hline
\end{tabular}

LUSC, lung squamous cell carcinoma; LUAD, lung adenocarcinoma.

Table VI. Value of miR-139-5p and miR-150-5p for survival prognosis.

\begin{tabular}{lcccccc}
\hline Cancer & $\begin{array}{c}\text { Total no. } \\
\text { of patients }\end{array}$ & $\begin{array}{c}\text { Living } \\
\text { patients }\end{array}$ & $\begin{array}{c}\text { Deceased } \\
\text { patients }\end{array}$ & Low risk & High risk & $\begin{array}{c}\text { Value of miRNA } \\
\text { for survival prognosis }\end{array}$ \\
\hline LUSC & 472 & 272 & 200 & 236 & 236 & $\mathrm{~S}=2.452 \times \mathrm{E}_{\text {miR-139-5p }}+0.173 \times \mathrm{E}_{\text {miR-150-5p }}$ \\
LUAD & 500 & 319 & 181 & 250 & 250 & $\mathrm{~S}=1.196 \times \mathrm{E}_{\text {miR-139-5p }}+2.693 \times \mathrm{E}_{\text {miR-150-5p }}$
\end{tabular}

LUSC, lung squamous cell carcinoma; LUAD, lung adenocarcinoma; miRNA, micro ribonucleic acid; S, survival; E, expression.

tumors and they display significant tissue specificity, which can serve as effective biomarkers for tracking the cancer of unknown origin (21). Previous studies have demonstrated that the miRNA expression profile is correlated with the survival of lung adenocarcinoma. Univariate analysis has shown that the high expression of hsa-mir-155 and low expression of hsa-let-7a-2 are correlated with the low survival rate, while multivariate analysis have revealed that hsa-mir-155 is still related to the survival rate, and the miRNA expression profile is a diagnostic and prognostic marker for lung cancer (22). The above results also suggest that the expression of miRNA in NSCLC is different from that of mRNA $(23,24)$. The role of
miRNA in the overall survival of patients with NSCLC has been analyzed currently, which may provide valuable information for the treatment of NSCLC (25). However, its expression in lung cancer tissues was less consistent in the previous studies. Whether the lung cancer stage, case type and smoking status affect the results is worthy of further exploration and analysis. The low expression of cell adhesion molecule 1 (CADM1) is closely related to the short survival of NSCLC (26), and it is essential to search for new markers.

In the present study, five miRNAs were selected and verified via RT-qPCR with an expanded sample size, and it was found that both miR-139-5p and miRNA-150-5p were downregulated, 
which is consistent with the GeneChip results. It is also reported that miR-139-5p is significantly downregulated in primary NSCLC tissues and cell lines. On the one hand, the ectopic expression of miR-139-5p significantly inhibits cell growth through suppressing the upregulation of cyclin D1 and p57 (Kip2), on the other hand, miR-139-5p induces apoptosis through upregulating cleaved caspase-3, a key apoptotic gene, and downregulating Bcl-2, an anti-apoptotic gene. In addition, miR-139-5p inhibits cell migration through inhibiting matrix metalloproteinase (MMP)-7 and MMP-9, and it was also found that miR-139-5p inhibits cell proliferation and metastasis promoting apoptosis through targeting oncogenic c-Met, thus playing a key role in lung cancer (27). In primary NSCLC, the miR-139 silencing mediated by histone H3 lysine 27 trimethylation (H3K27me3) enhances the distant lymph node metastasis and histological invasion (lymphatic invasion and vascular invasion) of NSCLC (28). Moreover, miR-139-5p inhibits in vitro proliferation, migration and invasion of lung cancer cells through targeting the insulin-like growth factor 1 receptor (IGF1R) (29). miRNA-150-5p has not been reported in NSCLC in detail, however it has been reported that miRNA-150-5p and miRNA-34c-3p are closely related to skeletal muscle mitochondrial function in human body (30), and the downregulation of miR-150-5p, a new circulating biomarker for acute heart failure (AHF), is correlated with the pathophysiology of AHF (31). In multiple myeloma, miR-150-5p arouses the specific effect of glucocorticoid receptor (GR) to increase the therapeutic response of glucocorticoids through indirectly regulating the interaction of GR with transcription factors and GR chaperones and motivating mRNA of various effectors, protein stress and chemokines of GR (32). In future research, the role of downregulation of miR-139-5p and miR-150-5p in NSCLC needs to be further clarified, and their specific values in target genes and functions should also be determined.

In the present study, the enrichment analysis of the functions of target genes of differentially expressed miRNAs revealed that they mainly influence the binding process of intracellular components to protein, the positive regulation of biological process and the regulation of the metabolic process. Moreover, KEGG pathway enrichment analysis showed that these target genes are mainly enriched in the immunity, gene expression, metabolism and signal transduction, among which signal transduction is enriched with the most genes. It was confirmed by previous studies that inhibiting miR-192 and miR-662 reduces the clonality and motility of early squamous cell carcinoma cells and increases the sensitivity to etoposide (33). Downregulation of miR-30a-5p and upregulation of miR-210-3p in NSCLC have excellent sensitivity and acceptable specificity, which can assist in distinguishing cancer and non-cancer tissues (34). The chronic treatment of NSCLC with gefitinib will alter the miRNA expression, including the significant decline in miR-155 and miR-200c accompanied by epidermal growth factor receptor (EGFR) mutation, and the decline in miR-155 and miR-200c may be correlated with epithelial-mesenchymal transition and histone modification, which may reduce the sensitivity to gefitinib, independent of the secondary EGFR mutation (35). miRNA may play a role in immune escape, resistance to chemotherapeutic drugs and biological functions of lung cancer cells. Research on the roles of miR-139-5p and miR-150-5p in diagnosis, metabolism, signal transduction, biological behaviors and drug resistance in NSCLC will benefit the diagnosis and treatment of lung cancer patients, and may even bring an unexpected breakthrough in immunotherapy.

In conclusion, in the present investigation through GeneChip, it was revealed that miRNAs are mainly downregulated in the miRNA expression profile of lung cancer tissues in the middle-altitude area, which is not completely consistent with the miRNA expression difference in NSCLC tissues as reported by previous studies, indicating the individual difference and complexity of miRNA in pathogenesis. According to the verification with an expanded sample size, both miR-139-5p and miR-150-5p are downregulated, thus, deeply exploring their important roles in the occurrence and development of disease and regulation of tumor cell functions has great clinical value in the diagnosis, treatment and evaluation of lung cancer.

\section{Acknowledgements}

Not applicable.

\section{Funding}

The study was funded by the Fundamental Research for Application Project of the Qinghai Science and Technology Department (project no. 2016-ZJ-778).

\section{Availability of data and materials}

The datasets used and/or analyzed during the current study are available from the corresponding author on reasonable request.

\section{Authors' contributions}

YG wrote the manuscript and was responsible for the immunohistochemistry. YG and XS performed PCR. XW and XL were responsible for GeneChip scanning of lung cancer tissues. YG and YX assisted with statistical analysis. All authors read and approved the final manuscript.

\section{Ethics approval and consent to participate}

The study was approved by the Ethics Committee of Qinghai Provincial People's Hospital (Xining, China) (approval no. 2015-07); and informed consents were signed by the patients and/or their guardians.

\section{Patient consent for publication}

Not applicable.

\section{Competing interests}

The authors declare that they have no competing interests.

\section{References}

1. Schreiber G and McCrory DC: Performance characteristics of different modalities for diagnosis of suspected lung cancer: Summary of published evidence. Chest 123 (Suppl 1): 115S-128S, 2003. 
2. Markou A, Sourvinou I, Vorkas PA, Yousef GM and Lianidou E: Clinical evaluation of microRNA expression profiling in non small cell lung cancer. Lung Cancer 81: 388-396, 2013.

3. Solomides CC, Evans BJ, Navenot JM, Vadigepalli R, Peiper SC and Wang ZX: MicroRNA profiling in lung cancer reveals new molecular markers for diagnosis. Acta Cytol 56: 645-654, 2012.

4. Landi MT, Zhao Y, Rotunno M, Koshiol J, Liu H, Bergen AW, Rubagotti M, Goldstein AM, Linnoila I, Marincola FM, et al: MicroRNA expression differentiates histology and predicts survival of lung cancer. Clin Cancer Res 16: 430-441, 2010.

5. Petriella D, De Summa S, Lacalamita R, Galetta D, Catino A, Logroscino AF, Palumbo O, Carella M, Zito FA, Simone G, et al: miRNA profiling in serum and tissue samples to assess noninvasive biomarkers for NSCLC clinical outcome. Tumour Biol 37: 5503-5513, 2016.

6. Heller G, Altenberger C, Steiner I, Topakian T, Ziegler B, Tomasich E, Lang G, End-Pfützenreuter A, Zehetmayer S, Döme B, et al: DNA methylation of microRNA-coding genes in non-small-cell lung cancer patients. J Pathol 245: 387-398, 2018.

7. van Rooij E: The art of microRNA research. Circ Res 108 : 219-234, 2011

8. Pedersen AK, Mendes Lopes de Melo J, Mørup N, Tritsaris K and Pedersen SF: Tumor microenvironment conditions alter Akt and $\mathrm{Na}^{+} / \mathrm{H}^{+}$exchanger NHE1 expression in endothelial cells more than hypoxia alone: Implications for endothelial cell function in cancer. BMC Cancer 17: 542, 2017.

9. Petrova V, Annicchiarico-Petruzzelli M, Melino G and Amelio I: The hypoxic tumour microenvironment. Oncogenesis 7: 10, 2018

10. Lanikova L, Reading NS, Hu H, Tashi T, Burjanivova T, Shestakova A, Siwakoti B, Thakur BK, Pun CB, Sapkota A, et al: Evolutionary selected Tibetan variants of HIF pathway and risk of lung cancer. Oncotarget 8: 11739-11747, 2017.

11. Mirsadraee S, Oswal D, Alizadeh Y, Caulo A and van Beek E Jr: The 7th lung cancer TNM classification and staging system: Review of the changes and implications. World J Radiol 4: 128-134, 2012

12. Livak KJ and Schmittgen TD: Analysis of relative gene expression data using real-time quantitative PCR and the 2(-Delta Delta C(T)) method. Methods 25: 402-408, 2001.

13. Irizarry RA, Hobbs B, Collin F, Beazer-Barclay YD, Antonellis KJ, Scherf U and Speed TP: Exploration, normalization, and summaries of high density oligonucleotide array probe level data. Biostatistics 4: 249-264, 2003.

14. Dweep H and Gretz N: miRWalk2.0: A comprehensive atlas of microRNA-target interactions. Nat Methods 12: 697, 2015.

15. Ashburner M, Ball CA, Blake JA, Botstein D, Butler H, Cherry JM, Davis AP, Dolinski K, Dwight SS, Eppig JT, et al: Gene ontology: Tool for the unification of biology. The Gene Ontology Consortium. Nat Genet 25: 25-29, 2000

16. Kanehisa $M$ and Goto S: KEGG: kyoto encyclopedia of genes and genomes. Nucleic Acids Res 28: 27-30, 2000.

17. Lin PY, Yu SL and Yang PC: MicroRNA in lung cancer. Br J Cancer 103: 1144-1148, 2010

18. Wang Q, Wang S, Wang H, Li P and Ma Z: MicroRNAs: Novel biomarkers for lung cancer diagnosis, prediction and treatment. Exp Biol Med (Maywood) 237: 227-235, 2012.

19. Vannini I, Fanini F and Fabbri M: MicroRNAs as lung cancer biomarkers and key players in lung carcinogenesis. Clin Biochem 46: 918-925, 2013.

20. Lu J, Getz G, Miska EA, Alvarez-Saavedra E, Lamb J, Peck D, Sweet-Cordero A, Ebert BL, Mak RH, Ferrando AA, et al: MicroRNA expression profiles classify human cancers. Nature 435: 834-838, 2005.

21. Rosenfeld N, Aharonov R, Meiri E, Rosenwald S, Spector Y, Zepeniuk M, Benjamin H, Shabes N, Tabak S, Levy A, et al: MicroRNAs accurately identify cancer tissue origin. Nat Biotechnol 26: 462-469, 2008.

22. Yanaihara N, Caplen N, Bowman E, Seike M, Kumamoto K, Yi M, Stephens RM, Okamoto A, Yokota J, Tanaka T, et al: Unique microRNA molecular profiles in lung cancer diagnosis and prognosis. Cancer Cell 9: 189-198, 2006.
23. Boutros PC, Lau SK, Pintilie M, Liu N, Shepherd FA, Der SD, Tsao MS, Penn LZ and Jurisica I: Prognostic gene signatures for non-small-cell lung cancer. Proc Natl Acad Sci USA 106: 2824-2828, 2009.

24. Hou J, Aerts J, den Hamer B, van Ijcken W, den Bakker M, Riegman P, van der Leest C, van der Spek P, Foekens JA, Hoogsteden HC, et al: Gene expression-based classification of non-small cell lung carcinomas and survival prediction. PLoS One 5: e10312, 2010.

25. Yu N, Zhang Q, Liu Q, Yang J and Zhang S: A meta-analysis: microRNAs' prognostic function in patients with nonsmall cell lung cancer. Cancer Med 6: 2098-2105, 2017.

26. Botling J, Edlund K, Lohr M, Hellwig B, Holmberg L, Lambe M, Berglund A, Ekman S, Bergqvist M, Pontén F, et al: Biomarker discovery in non-small cell lung cancer: Integrating gene expression profiling, meta-analysis, and tissue microarray validation. Clin Cancer Res 19: 194-204, 2013.

27. Sun C, Sang M, Li S, Sun X, Yang C, Xi Y, Wang L, Zhang F, $\mathrm{Bi} \mathrm{Y}, \mathrm{Fu} \mathrm{Y}$, et al: Hsa-miR-139-5p inhibits proliferation and causes apoptosis associated with downregulation of c-Met. Oncotarget 6: 39756-39792, 2015.

28. Watanabe K, Amano Y, Ishikawa R, Sunohara M, Kage H, Ichinose J, Sano A, Nakajima J, Fukayama M, Yatomi Y, et al: Histone methylation-mediated silencing of miR-139 enhances invasion of non-small-cell lung cancer. Cancer Med 4: 1573-1582, 2015.

29. Xu W, Hang M, Yuan CY, Wu FL, Chen SB and Xue K: MicroRNA-139-5p inhibits cell proliferation and invasion by targeting insulin-like growth factor 1 receptor in human non-small cell lung cancer. Int J Clin Exp Pathol 8: 3864-3870, 2015.

30. Dahlmans D, Houzelle A, Andreux P, Jörgensen JA, Wang X, de Windt LJ, Schrauwen P, Auwerx J and Hoeks J: An unbiased silencing screen in muscle cells identifies miR-320a, miR-150, miR-196b, and miR-34c as regulators of skeletal muscle mitochondrial metabolism. Mol Metab 6: 1429-1442, 2017.

31. Scrutinio D, Conserva F, Passantino A, Iacoviello M, Lagioia R and Gesualdo L: Circulating microRNA-150-5p as a novel biomarker for advanced heart failure: A genome-wide prospective study. J Heart Lung Transplant 36: 616-624, 2017.

32. Palagani A, Op de Beeck K, Naulaerts S, Diddens J, Sekhar Chirumamilla C, Van Camp G, Laukens K, Heyninck K, Gerlo S, Mestdagh P, et al: Ectopic microRNA-150-5p transcription sensitizes glucocorticoid therapy response in MM1S multiple myeloma cells but fails to overcome hormone therapy resistance in MM1R cells. PLoS One 9: e113842, 2014.

33. Filipska M, Skrzypski M, Czetyrbok K, Stokowy T, Stasiłojć G, Supernat A, Jassem J, Żaczek AJ and Bigda J: miR-192 and miR-662 enhance chemoresistance and invasiveness of squamous cell lung carcinoma. Lung Cancer 118: 111-118, 2018.

34. Świtlik W, Karbownik MS, Suwalski M, Kozak J and Szemraj J: miR-30a-5p together with miR-210-3p as a promising biomarker for non-small cell lung cancer: A preliminary study. Cancer Biomark 21: 479-488, 2018.

35. Narita M, Shimura E, Nagasawa A, Aiuchi T, Suda Y, Hamada Y, Ikegami D, Iwasawa C, Arakawa K, Igarashi K, et al: Chronic treatment of non-small-cell lung cancer cells with gefitinib leads to an epigenetic loss of epithelial properties associated with reductions in microRNA-155 and -200c. PLoS One 12: e0172115, 2017.

This work is licensed under a Creative Commons Attribution-NonCommercial-NoDerivatives 4.0 International (CC BY-NC-ND 4.0) License. 